\title{
Effects of Gaseous Sulphuric Acid on Diesel Exhaust Nanoparticle Formation and Characteristics
}

\author{
Topi Rönkkö, ${ }^{*}{ }^{\dagger}$ Tero Lähde, ${ }^{\dagger}$ Juha Heikkilä, ${ }^{\dagger}, \#$ Liisa Pirjola, ${ }^{\ddagger}$ Ulrike Bauschke, ${ }^{\S}$ Frank Arnold, ${ }^{\S}$ \\ Hans Schlager," Dieter Rothe, ${ }^{\perp}$ Jaakko Yli-Ojanperä, ${ }^{\dagger}$ and Jorma Keskinen ${ }^{\dagger}$ \\ ${ }^{\dagger}$ Aerosol Physics Laboratory, Department of Physics, Tampere University of Technology, P.O. Box 599, FIN-33720, Tampere, \\ Finland \\ ${ }^{\ddagger}$ Department of Technology, Metropolia University of Applied Sciences, P.O. Box 4000, FIN-00180, Helsinki, Finland \\ ${ }^{\S}$ Atmospheric Physics Division, Max Planck Institute for Nuclear Physics (MPIK), P.O. Box 103980, D-69029 Heidelberg, Germany \\ "Deutsches Zentrum für Luft- und Raumfahrt (DLR), Oberpfaffenhofen, 82234 Wessling, Germany \\ ${ }^{\perp}$ MAN Truck \& Bus AG, EMRE, Engine Research Exhaust Aftertreatment, Vogelweiherstrasse 33, 90441 Nürnberg, Germany
}

ABSTRACT: Diesel exhaust gaseous sulphuric acid (GSA) concentrations and particle size distributions, concentrations, and volatility were studied at four driving conditions with a heavy duty diesel engine equipped with oxidative exhaust after-treatment. Low sulfur fuel and lubricant oil were used in the study. The concentration of the exhaust GSA was observed to vary depending on the engine driving history and load. The GSA affected the volatile particle fraction at high engine loads; higher GSA mole fraction was followed by an increase in volatile nucleation particle concentration and size as well as increase of size of particles possessing nonvolatile core. The GSA did not affect the number of nonvolatile particles. At low and medium loads, the exhaust GSA concentration was low and any GSA driven changes in particle population were not observed. Results show that during the exhaust cooling and dilution processes, besides critical in volatile nucleation particle formation, GSA can change the characteristics of all nucleation mode particles. Results show the dual nature of the nucleation mode particles so that the nucleation mode can include simultaneously volatile and nonvolatile particles, and fulfill the previous results for the nucleation mode formation, especially related to the role of GSA in formation processes.

\section{INTRODUCTION}

The submicrometer diesel exhaust particles are typically divided into two separate groups, which are frequently seen in exhaust particle number size distribution as separate modes, usually called as an accumulation or a soot mode and a nucleation mode. ${ }^{1}$ Accumulation mode particles consist of nonvolatile, carbonaceous soot agglomerates formed in combustion process and semivolatile surface species. Nucleation mode particles, on the other hand, consist mainly (by volume) of volatile components, such as water, sulphuric compounds, and hydrocarbons, ${ }^{1-4}$ but may contain also nonvolatile compounds. ${ }^{5-8}$ The mean particle diameters of the nucleation mode and the accumulation mode are typically between 3 and $30 \mathrm{~nm}$ and 40 and $100 \mathrm{~nm}$, respectively. In addition to their different compositions and sizes, one difference between the particle modes comes from their response to the dilution and cooling conditions: typically the nucleation mode particle diameters and frequently also the number concentrations change strongly with changing dilution conditions, whereas the accumulation mode size and number may be considered unchanged. $^{9-11}$

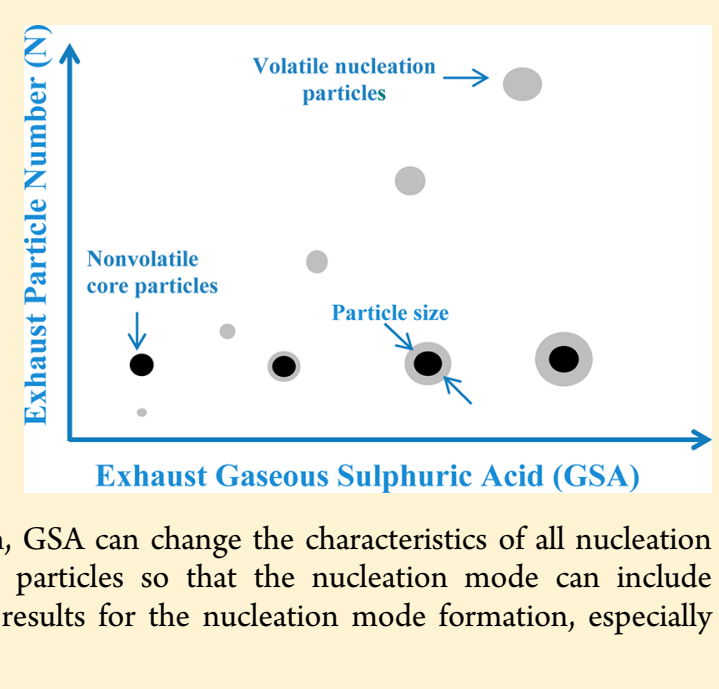

Because of the small particle size and thus low mass emission levels, present regulation do not focus directly on nucleation mode particle emissions. Limits and regulation, however, have indirect effects on the nucleation particle formation and emissions. For instance, emission limits for hydrocarbons and carbon monoxide have caused the wide use of oxidative exhaust aftertreatment which enhances the nucleation mode particle formation. ${ }^{12-15}$ On the other hand, the decrease in fuel sulfur content (FSC), forced by legislation, seems to limit the number of the occasions when the nucleation mode is detected but, however, not suppress them totally. ${ }^{13-16}$

The gaseous sulphuric acid (GSA), originated from fuel and lubricant oil sulfur compounds, is still suspected as a one of the most important compounds initiating the volatile nucleation mode particle formation in cooling dilution. Especially, if the vehicle or engine is equipped with a diesel particle filter (DPF) and if it operates at high load, the nucleation mode detection is

Received: June 17, 2013

Revised: August 23, 2013

Accepted: September 17, 2013

Published: September 17, 2013 
Table 1. Driving Parameters and Regulated Particle and NOx Emissions

\begin{tabular}{|c|c|c|c|c|c|c|c|c|}
\hline load $(\%) / E S C$ mode number & $\begin{array}{l}\text { engine speed } \\
(\mathrm{rpm})\end{array}$ & $\begin{array}{l}\text { torque } \\
(\mathrm{Nm})\end{array}$ & $\begin{array}{l}\text { power } \\
(\mathrm{kW})\end{array}$ & air mass flow $(\mathrm{kg} / \mathrm{h})$ & fuel consumption $(\mathrm{kg} / \mathrm{h})$ & $\begin{array}{l}\text { exhaust temperature } \\
\left({ }^{\circ} \mathrm{C}\right)\end{array}$ & $\begin{array}{c}\text { PM } \\
(\mathrm{mg} / \mathrm{kWh})\end{array}$ & $\begin{array}{c}\mathrm{NO}_{x} \\
(\mathrm{~g} / \mathrm{kWh})\end{array}$ \\
\hline $100 / 10$ & 1800 & 1660 & 314 & 1460 & 64 & $427 \pm 2$ & 16 & 3.3 \\
\hline $75 / 12$ & 1800 & 1260 & 237 & 1270 & 50 & $384 \pm 1$ & 13 & 3.5 \\
\hline $50 / 13$ & 1800 & 838 & 158 & 1030 & 35 & $345 \pm 1$ & 24 & 3.5 \\
\hline $25 / 11$ & 1800 & 418 & 79 & 729 & 21 & $296 \pm 1$ & 68 & 3.3 \\
\hline
\end{tabular}

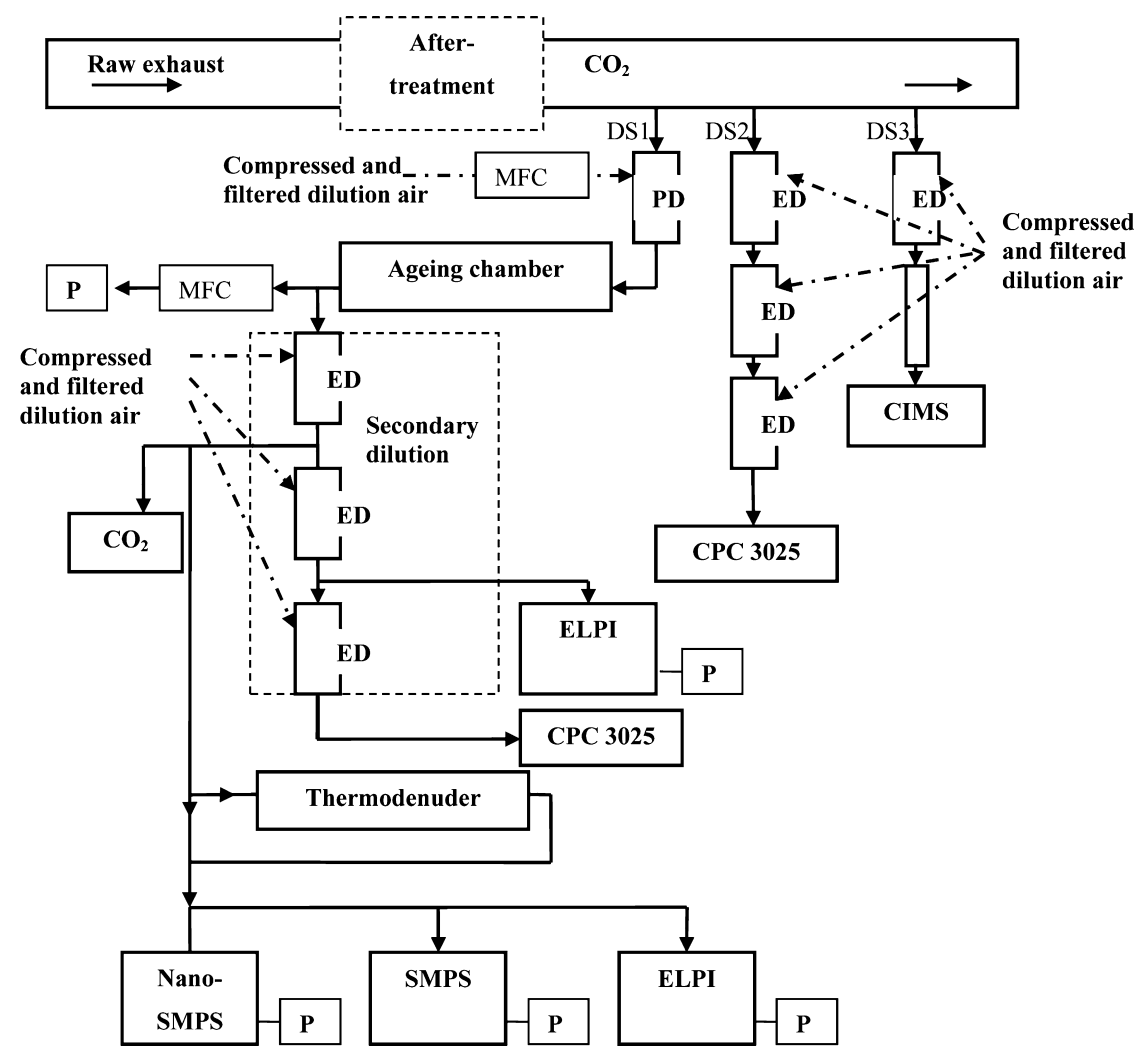

Figure 1. The measurement setup. Sample flow control was conducted using pumps (P) and mass flow controllers (MFC); sample was diluted using porous tube diluter (PD) and ejector type diluters (ED). Three different dilution systems were used (DS1, DS2, and DS3).

connected to $\mathrm{GSA}^{15}$ or more generally, sulfur containing compounds. ${ }^{13,14,17-20}$ The nucleation mode particles, downstream DPF, are electrically neutral and evaporate at temperatures above $150{ }^{\circ} \mathrm{C}^{8}$ and grow through the humidification like sulphates. ${ }^{21}$ Nevertheless, the nucleation mode is measured also in conditions where nucleation cannot be explained with sulfur species. $^{7,8,22-24}$ In case of modern engines without exhaust after-treatment or with low particle collection efficiency aftertreatment, and with low FSC fuel, the nucleation mode is repeatedly shown to include nonvolatile compounds (core particle) and electric charge. ${ }^{7,8,23-25}$ In contrary to sulfur driven nucleation particle formation in cooling exhaust, electric properties of the core particles, ${ }^{8,23}$ clear trade-off between soot particle emission and core particle emission ${ }^{24}$ and the effects of particle filtration systems ${ }^{8,25}$ strongly indicates that the core particles are formed at high temperature conditions, most likely in the combustion chamber. However, the exact formation mechanism and the composition of core particles are unknown, partly because of limited experimental data and experimental challenges caused by small core particle size. The core particle number concentration seems to be independent of the dilution conditions, but the nucleation mode diameter, with or without a core, still responds to condensing species in exhaust dilution process. ${ }^{7}$
The growth of the core particles during the exhaust dilution and cooling is dominated by the condensation of hydrocarbon species when after-treatment is not used. ${ }^{7}$ However, the core is shown to exist also after a diesel oxidation catalyst (DOC). ${ }^{8}$ Because DOC reduces exhaust hydrocarbon concentration and enhances $\mathrm{SO}_{2}$ to $\mathrm{SO}_{3}$ conversion ${ }^{13,14}$ leading to the formation of GSA, ${ }^{12,15}$ it can change the growth process of the core particles and even cause the nucleation in cooling dilution. Although the existence of core particles with DOC has been observed, ${ }^{8}$ results related to core particle growth with sulphuric species remain elusive. One of the problems may be the simultaneity of the condensation of sulphuric species on core particles and the formation of new particles via nucleation of GSA and water. Because the core diameter is typically below 7 $\mathrm{nm},{ }^{7,8,23-25}$ the simultaneous processes of condensation and nucleation may result in one externally mixed particle mode where particles formed through different processes are difficult to separate.

In this paper, simultaneously measured diesel exhaust particle characteristics and exhaust gaseous sulphuric acid (GSA) concentrations are presented. Compared to the study of Arnold et al., ${ }^{15}$ where the effect of exhaust aftertreatment and fuel sulfur content on on exhaust GSA concentrations were studied, here the special attention is given to the dual nature of 
nucleation mode particles. The major objectives are to show the effects of GSA separately on the volatile nucleation mode and on the core mode and to clarify the role of gas-to-liquid conversion from the viewpoint of final exhaust particle number and volume concentration.

\section{EXPERIMENTAL SECTION}

Exhaust measurements were performed at the engine dynamometer of MAN for a six-cylinder turbo-charged common rail heavy-duty diesel engine equipped with EGR (displacement $10.5 \mathrm{dm}^{3}$, max. power $324 \mathrm{~kW}$ at1900 $\mathrm{min}^{-1}$, max. torque $2100 \mathrm{~N} \mathrm{~m}$ at $1000-1400 \mathrm{~min}^{-1}$, emission level Euro IV if equipped with PM-KAT). In this study, the engine was equipped with the combination of the diesel oxidation catalyst and partial diesel particle filter $(\mathrm{DOC}+\mathrm{pDPF}){ }^{25}$ The length of DOC was $75 \mathrm{~mm}$, diameter was $334 \mathrm{~mm}$, cell density $200 \mathrm{cpsi}$, and platinum content $1.4 \mathrm{~g} / \mathrm{dm}^{3}$. The length of pDPF was $225 \mathrm{~mm}$, diameter was $334 \mathrm{~mm}$, cell density $300 \mathrm{cpsi}$, and platinum content $0.35 \mathrm{~g} / \mathrm{dm}^{3}$. The measurements were conducted at four engine load conditions (100\%, 75\%, 50\%, and $25 \%$ ) with engine speed $1800 \mathrm{rpm}$ (Table 1). Sulfur contents of diesel fuel and lubricating oil (SAE 10W-40) used in the measurements were 36 and $1600 \mathrm{ppm}$, respectively.

Three exhaust sampling and dilution systems were used: one (DS1) for the measurements of particle size distributions, particle volatility, and total particle number concentration (including volatile and nonvolatile particles), one for the measurements of total nonvolatile particle number (DS2), and one for the GSA measurements (DS3) (Figure 1). PM presented in Table 1 was sampled for filters using the NOVA Mikrotrol 4 microtunnel.

DS1 was a modified version of a partial flow sampling system, ${ }^{26}$ a relatively widely used system in nucleation mode particle characteristics studies. ${ }^{7-11,15,17,24,25}$ It consisted of a porous tube type primary diluter (PD), ${ }^{27}$ followed by an aging chamber and ejector type diluters (ED). In the PD, the dilution air temperature was $30{ }^{\circ} \mathrm{C}$ and the dilution ratio was 12 . Dilution ratios were calculated from $\mathrm{CO}_{2}$ concentrations of the diluted exhaust sample and raw exhaust. The relative humidity for the pressurized and filtered dilution air was close to zero. DS2 consisted of three ED (see Figure 1). In the first ED the dilution air was heated to $250{ }^{\circ} \mathrm{C}$, in the second and the third $\mathrm{ED}$ the dilution air temperature equaled to room temperature; the primary dilution was presumed to sufficient to prevent nucleation in the second and third dilution phase. In DS3, the dilution air was heated to $250{ }^{\circ} \mathrm{C}$ and the transfer line to 200 ${ }^{\circ} \mathrm{C}$ to prevent the new particle formation and wall losses of GSA.

After DS1, particle number size distributions were measured using two scanning mobility particle sizers $\left(\mathrm{SMPS}^{28}\right)$. One SMPS (later called Nano-SMPS) was equipped with DMA 3085 (TSI Inc.) and CPC 3025 (TSI Inc.) and the other with DMA 3071 (TSI Inc.) and CPC 3775 (TSI Inc.). Nano-SMPS was used in measurements with a size range of 3-60 nm and SMPS with a size range from 10 to $430 \mathrm{~nm}$. Nano-SMPS particle size distribution data were corrected for DMA losses and for CPC efficiency. SMPS particle size distribution data was not corrected apart from thermodenuder losses (see below). In the analyses we used Nano-SMPS data for particle size range 3-60 nm and SMPS data for size range of $60-430 \mathrm{~nm}$. Two electrical low pressure impactors (ELPI, Dekati Inc.) were used to monitor the stability of the particle emission during the SMPS scans. ${ }^{29}$ Particle volatility was studied with a thermodenuder (TD, see, for example, ref 26) where the diluted sample was heated to $265^{\circ} \mathrm{C}$ and after that, led into the denuder where the cooled inner wall was covered with active charcoal to collect evaporated compounds. The size distributions measured after the TD were corrected for particle losses. ${ }^{25}$ CPC 3025 after DS2 counted total particle number concentration of nonvolatile particles and thus named hereafter as $N_{\text {nonv }}$. Similarly, the CPC 3025 after DS1 counted the sum of nonvolatile particles and volatile particles, thus named hereafter as $N_{\text {all }}$.

The GSA concentration was measured using a Chemical Ionization Mass Spectrometer (CIMS), which consists of a flow tube reactor and an ion trap mass spectrometer. In the flow tube reactor gaseous $\mathrm{H}_{2} \mathrm{SO}_{4}$ molecules undergo an ion molecule reaction with the reagent ions $\left(\mathrm{NO}_{3}{ }^{-} \mathrm{HNO}_{3}\right)$ leading to product ions of the type $\mathrm{HSO}_{4}{ }^{-} \mathrm{HNO}_{3}$. The GSA concentration was determined from the abundance ratio of product and reagent ions measured with an ion trap mass spectrometer. Like in our previous study, ${ }^{15}$ the GSA detection limit is $4 \times 10^{5} \mathrm{~cm}^{-3}$, and the time response of the CIMS instrument is $1 \mathrm{~min}$. The uncertainty of the measured GSA concentrations of GSA present in the flow tube reactor is $\pm 30 \%$. More detailed information of the CIMS instrument and its use can be found in refs 15 and 30 .

\section{RESULTS}

Total Particle Number Concentration and Gaseous Sulphuric Acid (GSA). Exhaust particle and GSA measurements were performed first at $100 \%$ load driving condition (Table 1). Figure 2 shows the GSA mole fractions (GSAMF)

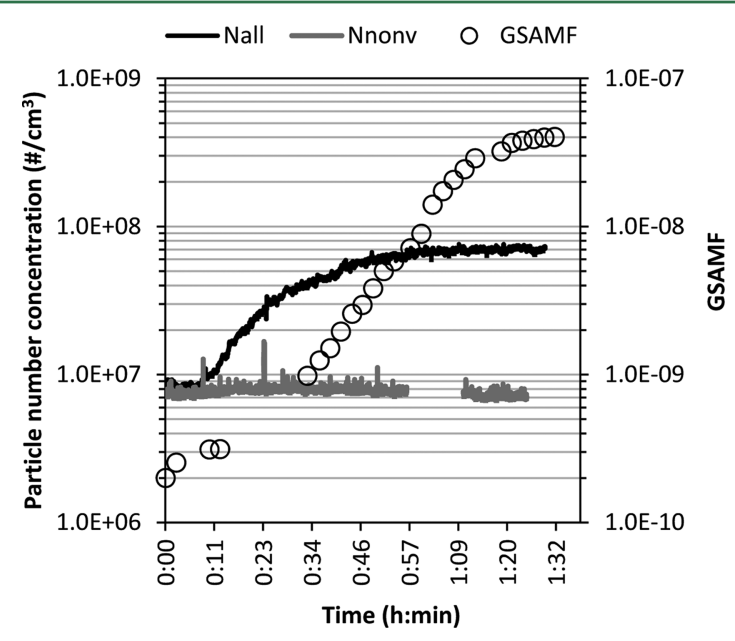

Figure 2. Total particle number concentration $\left(N_{\text {all }}\right)$, nonvolatile particle concentration $\left(N_{\text {nonv }}\right)$, and mole fraction of gaseous sulphuric acid (GSAMF) at $100 \%$ load, all calculated to raw exhaust and shown as a function of measurement time.

and particle concentrations $N_{\text {nonv }}$ and $N_{\text {all }}$ measured with two CPC 3025 and calculated to raw exhaust. During the measurement period, the GSAMF underwent a significant change from $2 \times 10^{-10}$ at the beginning to the $4 \times 10^{-8}$ at the end of the period, besides very steady engine operation. The change in particles may be resulted of the relatively fresh catalyst and it may indicate decrease of the sulfur compound storage during the measurement. While $N_{\text {nonv }}$ was practically constant during the whole measurement period, after short delay (first $10 \mathrm{~min}$ ) at the beginning of the measurement $N_{\text {all }}$ 
had an increasing pattern with time. After one hour, the increase of $N_{\text {all }}$ seemed to slow down so that $N_{\text {all }}$ was nearly constant although the GSAMF continued slight increasing. Any simple functional dependency between $N_{\text {all }}$ and GSAMF cannot be seen in Figure 2, which is likely caused by complexity of processes and exhaust particle population. However, this complexity can be significantly reduced by analyses of particle size distributions (see below). Anyway, the result indicates that the formation of nonvolatile particles was independent of the GSAMF, whereas an increase in the GSAMF (above $3 \times 10^{-10}$, see Figure 2) seems to cause the formation of new volatile particles in DS1 dilution and sampling system, that is, in cooling dilution.

Particle Size Distributions. Exhaust particle size distributions were measured after DS1. At 100\% load, all particle size distributions measured from thermodenuder treated exhaust sample were practically identical and consisted of two separable particle modes; the core mode (Geometric Mean Diameter (GMD) $10 \mathrm{~nm}$ ) and the soot mode (GMD $50 \mathrm{~nm}$ ). These size distributions were measured at different GSAMF levels. Thus the result indicates that the GSA plays no role in core and soot particle formation (Figure 3a). In addition, these identical

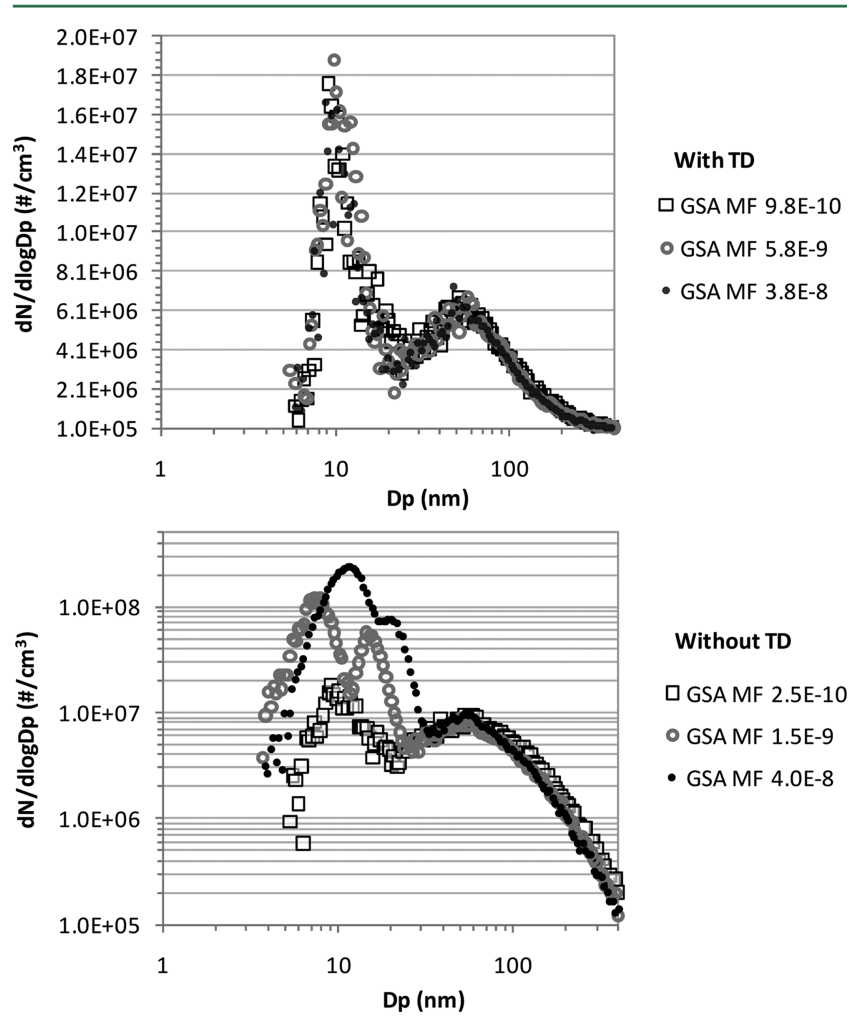

Figure 3. Particle number size distributions measured with nanoSMPS $\left(D_{\mathrm{p}}<60 \mathrm{~nm}\right)$ and SMPS $\left(D_{\mathrm{p}}>60 \mathrm{~nm}\right)$ after thermodenuder (TD) (a) and without TD (b) at different exhaust GSA mole fractions (GSAMF). Engine load was $100 \%$. Note different $y$-axis in figures.

nonvolatile particle size distributions at different GSA levels indicate that the volatile particle formation (see $N_{\text {all }}$ in Figure 2) do not affect the measured nonvolatile core particle mode. In other words, core particles are not residuals of the particles formed during exhaust dilution and cooling.

Figure $3 \mathrm{~b}$ shows the particle size distributions at three different exhaust GSA levels without TD treatment, all measured at $100 \%$ load. When the GSAMF was low (here $\left.2.5 \times 10^{-10}\right)$, the particle size distribution was similar like the size distribution of nonvolatile particles in TD treated sample, that is, any condensation on nonvolatile soot and core particles was not taken place or, if condensation took place, it did not have significant effect on the size of the particles. However, when the GSA mole fraction increased to $1.5 \times 10^{-9}$ the core mode shifted toward larger particle sizes, indicating that sulphuric acid and possibly organic acids ${ }^{15}$ condensed on core particle surfaces. The soot mode size remained unchanged which can be explained by agglomerated structure of soot particles, so that if condensation on soot particles occurs the condensate intake of the soot particles fills the void volumes of the particles without effect on mobility size distribution measured by SMPS. At the same time, also the third mode appeared. The third mode was detected only in distribution which was measured from sample without TD treatment, that is, it was volatile (later called volatile nucleation mode). The volatile nucleation mode was smaller in size compared to the core mode at low GSAMF levels or through TD; however, both the particles with nonvolatile core and the volatile nucleation particles increased in size when the GSAMF levels increased. At high GSAMF levels the volatile nucleation mode dominated the size distribution because of its higher number concentration.

Compared with several other studies, ${ }^{7,8,25}$ the core particle concentration was in this study relatively low $\left(1.3 \times 10^{7} \mathrm{\#} / \mathrm{cm}^{3}\right)$ and the core particle GMD was large, approximately $10 \mathrm{~nm}$. The reason for that is the use of DOC $+\mathrm{pDPF}$, which filtrates efficiently the smallest engine out core particles (particle diameter smaller than $9 \mathrm{~nm})^{25}$ and allow only part of largest core particles enter into the cooling dilution. Furthermore, the oxidative DOC + pDPF enhances $\mathrm{SO}_{2}$ to $\mathrm{SO}_{3}$ conversion and thus the formation of GSA and volatile nucleation particles, smaller in diameter than existing core particles. As a result, the particles with and without nonvolatile cores form two separable particle modes. In comparison, Lähde et al. ${ }^{8}$ showed the core particle existence with DOC. However, in that study the core mode GMD was smaller and if the nucleation mode measured without TD treatment consisted of volatile particles and particles possessing nonvolatile cores, they formed one externally mixed particle mode.

From the measured size distribution data, the GMDs as well as particle number and volume concentrations ( $\mathrm{N}$ and $\mathrm{V}$ ) can be calculated separately for each particle mode. In this study the GMD, $\mathrm{N}$ and $\mathrm{V}$ were calculated by fitting a bimodal log-normal distribution to the distribution measured with $\mathrm{TD}$, subtracting the soot mode (at $100 \%$ load, GMD $49 \mathrm{~nm}$, geometric standard deviation (GSD) 2.1, N $4.7 \times 10^{6} \mathrm{\#} / \mathrm{cm}^{3}$ ) from the distributions measured without TD and after that, by fitting two log-normal distributions for the remaining particle size distribution without the soot mode. Volume concentrations were calculated from fitted distributions assuming that the particles are spherical. Figure 4 shows GMD, N and V for the volatile nucleation particles and particles possessing nonvolatile cores at $100 \%$ load. Also the parameters of nonvolatile particle size distributions are shown (core mode and soot mode).

An increase in GSAMF was followed by an increase in both the volatile nucleation particle and the nonvolatile particle GMD (Figure 4a). The larger GMD of particles possessing nonvolatile cores, compared to the volatile nucleation mode $\mathrm{GMD}$, was a direct consequence of relatively large initial size of the core particles (gray line, Figure 4a).

As shown in Figure $4 b$, an increase in the GSAMF was followed by an increase in the volatile nucleation mode number 


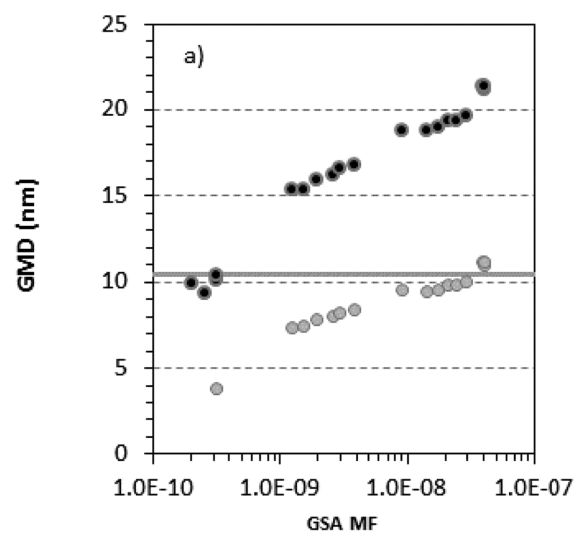

- Particles with nonvolatile core (w/o TD)

Nonvolatile core particles (with TD, mean value)

- Volatile nucleation particles (w/o TD)

— Soot particles (with TD, mean value)
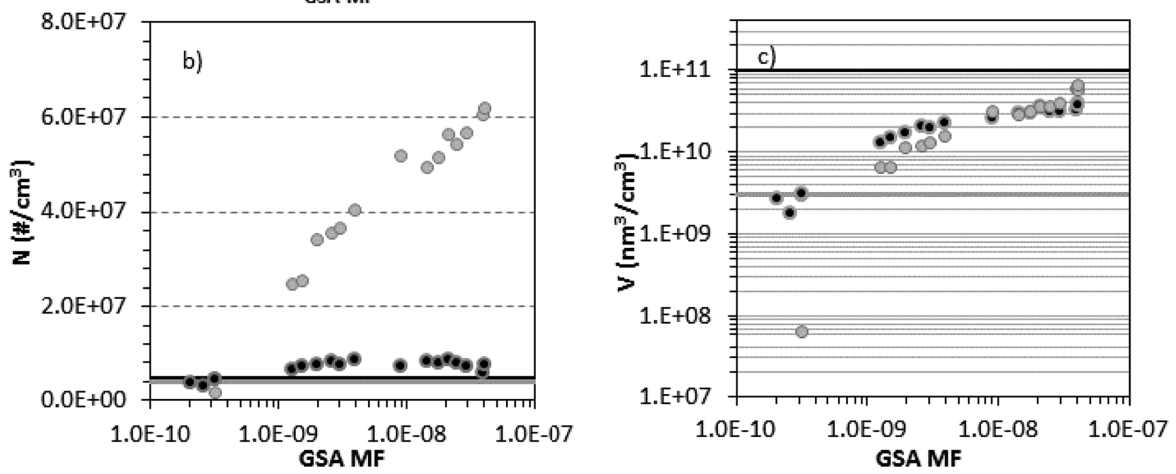

Figure 4. Geometric mean diameter (GMD) (a), raw exhaust number concentration $(N)$ (b) and volume concentration $(V)$ (c) of volatile nucleation mode particles and of particles possessing nonvolatile core as a function of raw exhaust mole fraction of gaseous sulphuric acid (GSAMF). Also mean GMD, $N$, and $V$ of nonvolatile modes, core mode and soot mode, measured with TD (horizontal lines) are shown. Engine load was $100 \%$.

Table 2. GSA Mole Fraction (GSAMF) and GMD and $N$ of Different Particle Modes ${ }^{a}$

\begin{tabular}{|c|c|c|c|c|c|c|c|c|c|}
\hline & & & volatile nuc & ion mode & particles & ossessing nonvol & cores & soot & \\
\hline $\begin{array}{l}\text { ESC mode } \\
\text { loa }\end{array}$ & ngine & GSAMF & $\begin{array}{c}\text { GMD w/o TD } \\
(\mathrm{nm})\end{array}$ & $\begin{array}{c}\text { N w/o TD } \\
\left(\# / \mathrm{cm}^{3}\right)\end{array}$ & $\begin{array}{c}\text { GMD w/o TD } \\
(\mathrm{nm})\end{array}$ & $\begin{array}{c}\text { GMD with TD } \\
(\mathrm{nm})\end{array}$ & $\begin{array}{c}\mathrm{N} \text { with TD } \\
\left(\# / \mathrm{cm}^{3}\right)\end{array}$ & $\begin{array}{l}\text { GMD with TD } \\
(\mathrm{nm})\end{array}$ & $\begin{array}{c}\mathrm{N} \text { with TD } \\
\left(\# / \mathrm{cm}^{3}\right)\end{array}$ \\
\hline $10 / 100 \%$ & first & $2 \times 10^{-10}$ & - & - & 10 & 10 & $3.9 \times 10^{6}$ & 49 & $4.7 \times 10^{6}$ \\
\hline & last & $4 \times 10^{-8}$ & 12 & $6.6 \times 10^{7}$ & 21 & & & & \\
\hline $12 / 75 \%$ & first & $1 \times 10^{-8}$ & - & - & 10 & 10 & $3.3 \times 10^{6}$ & 49 & $3.9 \times 10^{6}$ \\
\hline & last & $3 \times 10^{-8}$ & 7 & $4.8 \times 10^{6}$ & 15 & & & & \\
\hline $13 / 50 \%$ & first & $9 \times 10^{-9}$ & - & - & 9 & 9 & $8.9 \times 10^{5}$ & 56 & $1.1 \times 10^{7}$ \\
\hline & last & $5 \times 10^{-9}$ & - & - & 9 & & & & \\
\hline $11 / 25 \%$ & first & $3 \times 10^{-9}$ & - & - & - & - & - & 57 & $2.6 \times 10^{7}$ \\
\hline & last & $2 \times 10^{-9}$ & - & - & - & & & & \\
\hline
\end{tabular}

a"First" and "last" indicate the measurements at the beginning and at the end of measurement period, respectively, and "-" indicates that the particle mode was not detected.

concentration whereas the number concentration of the other mode remained practically constant at different GSA mole fractions. While the first indicates a GSA driven nucleation, the latter means that GSA did not affect the initial formation of core particles but, on the other hand, all core particles were activated to GSA driven growth during exhaust dilution and cooling process.

The GSA affected both the GMD and $N$ of volatile nucleation mode particles but only the GMD of particles possessing cores. As a consequence, the total volume concentration $(\mathrm{V})$ of the volatile nucleation mode reached the volume concentration of the core mode approximately at GSAMF level $1 \times 10^{-8}$. At higher GSAMF levels the volatile nucleation mode volume dominated (Figure 4c). Moreover, at the highest GSA levels the volume concentration of both nucleation modes were close to soot mode volume concentration. Hence, the nucleation mode particles may make significant contribution also for particulate matter mass (PM) emissions.

Effect of Engine Load. After the measurements at $100 \%$ load exhaust particle and GSA measurements were performed also at $75 \%, 50 \%$, and $25 \%$ loads (at ESC modes 12,13 , and 11 ), in this order. For these measurements, GSAMF and GMD and $N$ of different modes, all calculated to raw exhaust, are presented in Table 2. The first and the last values of the measurement periods are presented to show the changes, which are probably caused by the storage and/or release processes of sulfur compounds in the exhaust aftertreatment system. From Table 2, different trends for volatile and nonvolatile particle population can be seen.

The GSAMF was higher at high load conditions than at low load conditions. The difference is believed to be caused by 
higher exhaust temperatures and thus higher $\mathrm{SO}_{2}$ to $\mathrm{SO}_{3}$ conversion in the catalyst at high loads, and hence higher probability to GSA formation in the exhaust. GSA affected the volatile particle fraction only at high GSAMF levels; in particle size distributions the increase of GSAMF was followed by the increase of $\mathrm{N}$ and GMD of volatile nucleation mode particles and by the growth of the core mode GMD at $100 \%$ and $75 \%$ load. At 50\% and 25\% loads GSAMF was low and GSA driven effects in particle size distributions were not observed. The absence of the volatile nucleation mode is probably caused by the low GSA concentration, but also larger soot mode condensation sink for the GSA and coagulation sink for the nuclei further inhibit the volatile nucleation mode formation. $^{31,32}$

The number concentrations of soot mode and core mode particles were dependent on driving conditions (Table 2). Nonvolatile particle size distributions were nearly similar at $100 \%$ and $75 \%$ loads. However, at $50 \%$ and $25 \%$ loads the soot mode GMD and $N$ were clearly higher than at high loads and the core mode $N$ clearly lower. Although the correlation with GSA is at least qualitative, the trend in nonvolatile particle mode concentrations was not the consequence of changes in GSAMF; within one load (and measured with TD) both the soot mode and the core mode were independent of GSAMF (Figure 3a). The core-soot trade-off phenomenon is studied in detail by Lähde et al., ${ }^{24}$ and it seems to be the consequence of high temperature processes during and after the combustion.

\section{DISCUSSION}

The urban air particle number is frequently dominated by nucleation mode particles. Although in several countries the high quality diesel fuel is in use, and new diesel vehicles are typically equipped with modern emission reduction technologies because of the consecutive series of more stringent legislation, especially in developing countries diesel vehicles still represent one of the significant particulate pollution sources of urban environment. Nucleation mode has been observed essential part of diesel particulate matter especially from the viewpoint of exhaust particle number. Although the emission regulations do not set limits to diesel exhaust nucleation mode particle emissions, regulations affect the nucleation particle formation and emissions indirectly. For instance, emission limits for HC and CO have caused the wide use of DOC and limits for particulate emission have forced to use of advanced combustion control and diesel particle filters (DPF). On the other hand, the need of the oxidative aftertreatment systems has forced to limit the fuel sulfur content to ensure the aftertreatment proper functioning. All these actions taken to diminish the exhaust emissions affect also the exhaust GSA concentration increasing or decreasing it and, thus, to exhaust nucleation mode particle emissions. In this study, we focused on the diesel exhaust GSA and its effects on the exhaust nanoparticles in the case of a modern heavy duty diesel engine equipped with an oxidizing exhaust after-treatment system. We observed that even exhaust of one engine can be an externally mixed aerosol consisting of at least three significantly different particle types (Figure 5). These differences can affect, for example, the harmfulness of the particles and their lifetime and further evolution in the atmosphere.

The study produced strong experimental evidence that the formation of the volatile nucleation mode is a sulphuric acid driven process; at high load and above the GSA mole fraction 3 $\times 10^{-10}$ the increase in exhaust GSA concentration was

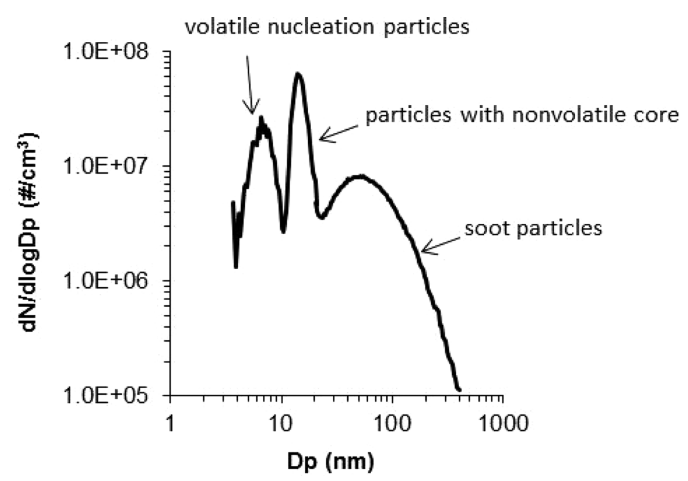

Figure 5. Size distribution of diesel exhaust particles with different characteristics and formation paths. Engine load 75\%, GSAMF $3 \times$ $10^{-8}$.

followed by an increase in the volatile nucleation mode particle number concentration and GMD. Even while using the low sulfur fuel, the exhaust GSA concentration was sufficient for volatile nucleation mode particle formation at the two highest engine loads. Thus, in countries like China and India where the fuel sulfur level is higher, the nucleation mode particle emission of traffic can be supposed to be high. However, at medium and low loads (low exhaust temperatures) volatile nucleation mode particle formation was not observed. On qualitative level our results are in line with prior experimental and modeling studies. $4,15,19-22,31,32$

The effect of GSA on the characteristics of nucleation mode particles possessing nonvolatile cores has been an open question. Because of the use of the $\mathrm{DOC}+\mathrm{pDPF}$ in our study, the GMD of the initial nonvolatile core particles was relatively large $(\sim 10 \mathrm{~nm})$ and the particles possessing the core were clearly separable from the volatile nucleation mode. We observed that GSA did not affect initial core particle formation and, more generally, the number concentration and size of dry nonvolatile particles (core particles and soot particles). However, the size of the core mode responded the increase of the GSAMF; the detected GMD of the core mode increased as the exhaust GSA concentration increased. This was caused by the condensation of compounds during the dilution and cooling of the sample. All the core particles were activated to this GSA driven growth. In real-world conditions the core particles are dispersed into ambient air and they interact with condensing gases forming a nucleation mode. ${ }^{7}$ Here the size distribution measurements were performed using the dilution system which mimics real-world dilution relatively well from the viewpoint of nucleation mode particle formation. ${ }^{33}$ Thus, this study indicates that the exhaust GSA level affect the realworld volatile particle size and number emission and the final size of particles possessing nonvolatile core, when oxidizing exhaust after-treatment is used. Thus the changes in exhaust GSA levels (due to the changes in FSC, engine oil sulfur content, exhaust after-treatment and driving conditions) would change the ambient air particle size distribution near highways as well as characteristics of the inhalation exposure. The possible health effects of diesel exhaust nucleation mode particles have been proposed to be of chemical nature due to the volatile material dissolution on the surfaces of human lung. ${ }^{34,35}$ The health effects of nonvolatile core particles are unknown. However, the lung deposition of the core particles may be still strongly dependent on the volatile fraction of the particles. ${ }^{35}$ Also, it should be noted that in addition to the 
significant effect of GSA on number emission, the size of volatile nucleation mode and core mode particles can grow even to such high sizes that these particles make significant contribution to the total exhaust particle volume and mass emissions.

\section{AUTHOR INFORMATION}

\section{Corresponding Author}

*E-mail: topi.ronkko@tut.fi. Phone: +358-40-1981019.

\section{Present Address}

\#Juha Heikkilä: Wärtsilä Finland Oy, Järvikatu 2-4, FIN-65200 Vaasa, Finland.

\section{Notes}

The authors declare no competing financial interest.

\section{ACKNOWLEDGMENTS}

This work was supported by The Finnish Funding Agency for Technology and Innovation (TEKES), Neste Oil Oyj and Ecocat Oy. We thank Tapio Aittokoski from Metropolia and Florian Lutz from MAN for technical support during the measurement campaign.

\section{REFERENCES}

(1) Kittelson, D. Engines and nanoparticles: A review. J. Aerosol Sci. 1998, 29, 575-588.

(2) Shi, J. P.; Khan, A. A.; Harrison, R. M. Measurements of ultrafine particle concentration and size distribution in the urban atmosphere. Sci. Total Environ. 1999, 235, 51-64.

(3) Tobias, H.; Beving, D.; Ziemann, P.; Sakurai, H.; Zuk, M.; McMurry, P.; Zarling, D.; Watylonis, R.; Kittelson, D. Chemical analysis of diesel engine nanoparticles using a nano-DMA/thermal desorption particle beam mass spectrometer. Environ. Sci. Technol. 2001, 35, 2233-2243.

(4) Schneider, J.; Hock, N.; Weimer, S.; Borrmann, S.; Kirchner, U.; Vogt, R.; Scheer, V. Nucleation particles in diesel exhaust: composition inferred from in situ mass spectrometer analysis. Environ. Sci. Technol. 2005, 39, 6153-6161.

(5) Abdul-Khalek, I.; Kittelson, D.; Graskow, B.; Wei, Q.; Brear, F. Diesel exhaust particle size: Measurement issues and trends. SAE Tech. Pap. Ser. 1998, No. 980525.

(6) Sakurai, H.; Tobias, H.; Park, K.; Zarling, D.; Docherty, K.; Kittelson, D.; McMurry, P.; Ziemann, P. On-line measurements of diesel nanoparticle composition and volatility. Atmos. Environ. 2003, 37, 1199-1210.

(7) Rönkkö, T.; Virtanen, A.; Kannosto, J.; Keskinen, J.; Lappi, M.; Pirjola, L. Nucleation mode particles with a nonvolatile core in the exhaust of a heavy duty diesel vehicle. Environ. Sci. Technol. 2007, 41, 6384-6389.

(8) Lähde, T.; Rönkkö, T.; Virtanen, A.; Schuck, T.; Pirjola, L.; Hämeri, K.; Kulmala, M.; Arnold, F.; Rothe, D.; Keskinen, J. Heavy duty diesel engine exhaust aerosol particle and ion measurements. Environ. Sci. Technol. 2009, 43, 163-168.

(9) Mathis, U.; Ristimäki, J.; Mohr, M.; Keskinen, J.; Ntziachristos, L.; Samaras, Z.; Mikkanen, P. Sampling conditions for the measurement of nucleation mode particles in the exhaust of a diesel vehicle. Aerosol Sci. Technol. 2004, 38, 1149-1160.

(10) Giechaskiel, B.; Ntziachristos, L.; Samaras, Z.; Scheer, V.; Casati, R.; Vogt, R. Formation potential of vehicle exhaust nucleation mode particles on-road and in the laboratory. Atmos. Environ. 2005, 39, 3191-3198.

(11) Rönkkö, T.; Virtanen, A.; Vaaraslahti, K.; Keskinen, J.; Pirjola, L.; Lappi, M. Effect of dilution conditions and driving parameters on nucleation mode particles in diesel exhaust: laboratory and on-road study. Atmos. Environ. 2006, 40, 2893-2901.

(12) Reiner, T.; Arnold, F. Laboratory flow reactor measurements of the reaction $\mathrm{SO} 3+\mathrm{H} 2 \mathrm{O}+\mathrm{M} \rightarrow \mathrm{H} 2 \mathrm{SO} 4+\mathrm{M}$ : Implications for gaseous $\mathrm{H} 2 \mathrm{SO} 4$ and aerosol formation in the plumes of jet aircraft. Geophys. Res. Lett. 1993, 20 (23), 2659-2662.

(13) Maricq, M.; Chase, R.; Xu, N.; Laing, P. The effects of the catalytic converter and fuel sulphur level on motor vehicle particulate matter emissions: Light duty diesel vehicles. Environ. Sci. Technol. 2002, 36, 283-289.

(14) Giechaskiel, B.; Ntziachristos, L.; Samaras, Z.; Casati, R.; Scheer, V.; Vogt, R. Effect of speed and speed-transition on the formation of nucleation mode particles from a light duty diesel vehicle. SAE Tech. Pap. Ser. 2007, No. 2007-01-1110.

(15) Arnold, F.; Pirjola, L.; Rönkkö, T.; Reichl, U.; Schlager, H.; Lähde, T.; Heikkilä, J.; Keskinen, J. First on-line measurements of sulphuric acid gas in modern heavy duty diesel engine exhaust: Implications for nanoparticle formation. Environ. Sci. Technol. 2012, 46, 11227-11234.

(16) Vogt, R.; Scheer, V.; Casati, R.; Benter, T. On-road measurements of particle emission in the exhaust plume of a diesel passenger car. Environ. Sci. Technol. 2003, 37, 4070-4076.

(17) Vaaraslahti, K.; Keskinen, J.; Giechaskiel, B.; Solla, A.; Murtonen, T.; Vesala, H. Effect of lubricant on the formation of heavy-duty diesel exhaust particles. Environ. Sci. Technol. 2005, 39, 8497-8504.

(18) Kittelson, D.; Watts, W.; Johnson, J.; Thorne, C.; Higham, C.; Payne, M.; Goodier, S.; Warrens, C.; Preston, H.; Zink, U.; Pickles, D.; Goersmann, C.; Twigg, M.; Walker, A.; Boddy, R. Effect of fuel and lube oil sulfur on the performance of a diesel exhaust gas continuously regenerating trap. Environ. Sci. Technol. 2008, 42, 9276-9282.

(19) Arnold, F.; Pirjola, L.; Aufmhoff, H.; Schuck, T.; Lähde, T.; Hämeri, K. First gaseous sulfuric acid measurements in automobile exhaust: Implications for volatile nanoparticle formation. Atmos. Environ. 2006, 40, 7097-7105.

(20) Du, H.; Yu, F. Nanoparticle formation in the exhaust of vehicles running on ultra-low sulfur fuel. Atmos. Chem. Phys. 2008, 8, 47294739.

(21) Grose, M.; Sakurai, H.; Savstrom, J.; Stolzenburg, M.; Watts, W.; Morgan, C.; Murray, I.; Twigg, M.; Kittelson, D.; McMurry, P. Chemical and physical properties of ultrafine diesel exhaust particles sampled downstream of a catalytic trap. Environ. Sci. Technol. 2006, 40, 5502-5507.

(22) Lemmetty, M.; Pirjola, L.; Mäkelä, J. M.; Rönkkö, T.; Keskinen, J. Computation of maximum rate of water-sulphuric acid nucleation in diesel exhaust. J. Aerosol Sci. 2006, 37, 1596-1604.

(23) Filippo, A.; Maricq, M. Diesel nucleation mode particles: Semivolatile or solid? Environ. Sci. Technol. 2008, 42, 7957-7962.

(24) Lähde, T.; Rönkkö, T.; Virtanen, A.; Solla, A.; Kytö, M.; Söderström, C.; Keskinen, J. Dependence between nonvolatile nucleation mode particle and soot number concentrations in an EGR equipped heavy duty diesel engine exhaust. Environ. Sci. Technol. 2010, 44, 3175-3180.

(25) Heikkilä, J.; Rönkkö, T.; Lähde, T.; Lemmetty, M.; Arffman, A.; Virtanen, A.; Keskinen, J.; Pirjola, L.; Rothe, D. Effect of open channel filter on particle emissions of modern diesel engine. J. Air Waste Manage. Assoc. 2009, 59, 1148-1154.

(26) Ntziachristos, L.; Giechaskiel, B.; Pistikopoulos, P.; Samaras, Z.; Mathis, U.; Mohr, M.; Ristimäki, J.; Keskinen, J.; Mikkanen, P.; Casati, R.; Scheer, V.; Vogt, R. Performance evaluation of a novel sampling and measurement system for exhaust particle characterization. SAE Tech. Pap. Ser. 2004, No. 2004-01-1439.

(27) Mikkanen, P.; Moisio, M.; Keskinen, J.; Ristimäki, J.; Marjamäki, M. Sampling method for particle measurements of vehicle exhaust. SAE Tech. Pap. Ser. 2001, No. 2001-01-0219.

(28) Wang, S. C.; Flagan, R. C. Scanning electrical mobility spectrometer. Aerosol Sci. Technol. 1990, 13, 230-240.

(29) Keskinen, J.; Pietarinen, K.; Lehtimäki, M. Electrical low pressure impactor. J. Aerosol Sci. 1992, 23, 353-360.

(30) Speidel, M.; Nau, R.; Arnold; Schlager, H.; Stohl, A. Sulfur dioxide measurements in the lower, middle and upper troposphere: Deployment of an aircraft-based chemical ionization mass spectrom- 
eter with permanent in-flight calibration. Atmos. Environ. 2007, 41, $2427-2437$.

(31) Vouitsis, E.; Ntziachristos, L.; Samaras, Z. Theoretical investigation of the nucleation mode formation downstream of diesel after-treatment devices. Aerosol Air Qual. Res. 2008, 8, 37-53.

(32) Lemmetty, M.; Rönkkö, T.; Virtanen, A.; Keskinen, J.; Pirjola, L. The effect of sulphur in diesel exhaust aerosol: models compared with measurements. Aerosol Sci. Technol. 2008, 42, 916-929.

(33) Keskinen, J.; Rönkkö, T. 2010. Can real-world diesel exhaust particle size distribution be reproduced in the laboratory? A critical review. J. Air Waste Manage. Assoc. 2010, 60, 1245-1255.

(34) Alföldy, B.; Giechaskiel, B.; Hofmann, W.; Drossinos, Y. Sizedistribution dependent lung deposition of diesel exhaust particles. J. Aerosol Sci. 2009, 40, 652-663.

(35) Giechaskiel, B.; Alföldy, B.; Drossinos, Y. A metric for health effects studies of diesel exhaust particles. J. Aerosol Sci. 2009, 40, 639651. 